University of South Carolina

Scholar Commons

Faculty Publications

Law School

7-2016

\title{
Child Protection Law as an Independent Variable
}

Josh Gupta-Kagan

University of South Carolina, jgkagan@law.sc.edu

Follow this and additional works at: https://scholarcommons.sc.edu/law_facpub

Part of the Family Law Commons, Juvenile Law Commons, and the Social Welfare Law Commons

\section{Recommended Citation}

Josh Gupta-Kagan, Child Protection Law as an Independent Variable, 54 FAM. CT. REV. 398 (2016).

This Article is brought to you by the Law School at Scholar Commons. It has been accepted for inclusion in Faculty

Publications by an authorized administrator of Scholar Commons. For more information, please contact

digres@mailbox.sc.edu. 


\title{
CHILD PROTECTION LAW AS AN INDEPENDENT VARIABLE
}

\author{
Josh Gupta-Kagan*
}

Child protection professionals work in a multidisciplinary system in which the law and the family court play central roles and which collects an increasing amount of data. Yet we know little about what impact the law has on whether a child is removed by child protective services, is deemed neglected by a family court, or reunifies with a parent. Do state-to-state variations in child protection laws, or changes by individual states to their laws, lead to different outcomes for children and families? The dramatic variations in child welfare practice from one state to another suggest that legal variations do matter. Yet empirical research on these questions is scarce both because we collect too little data to measure all such issues, and, because we have failed to study the data we do have. This article is a plea for researchers to rectify that problem and for policymakers to improve data collection. Doing so would facilitate a more clear understanding of the law's effect on child protection outcomes and aid policymakers and advocates in identifying both promising and problematic practices and legal reforms.

Key Points for the Family Court Community:

- Significant legal variations exist between states and may help explain different outcomes in different state child protection systems.

- The child protection field now collects large amounts of data, but little data focused on legal procedures or substantive legal differences from state to state. As a result, the field knows relatively little about how legal variables affect outcomes.

- A better understanding of the impact on legal variables will help answer important policy, advocacy, and academic questions about child protection law and family courts.

- This article argues for reforms to data collection policies to enable further study of legal variables and for researchers to make greater use of existing data.

Keywords: Child Protection System; Child Welfare; Empirical/Statistical Data; Family Court; and State Law \& Policy.

\section{INTRODUCTION}

Child protection professionals work in a multidisciplinary system in which the law and the family court play central roles. Yet we know little about what impact the law has on whether a child is removed by child protective services, is adjudicated neglected by a family court, or is reunified with a parent. Do state-to-state variations in child protection laws or changes by individual states to their laws lead to different outcomes for children and families? Empirical research on this questions is scarce. This scarcity is both because we collect too little data to measure all such issues, and, because we have failed to study the data we do have. This article is a plea for researchers to rectify that problem and for policymakers to improve data collection policies to help research the law's effect on child protection outcomes.

We live in an era of big data, and child protection is no exception. We are awash in local, state, and federally reported data, and we work in a multidisciplinary field in which empirical studies are now common and have undoubtedly advanced our field. We have a much better understanding today than, say, twenty years ago of what factors place children most at risk, how such factors correlate with family court decisions, how removal from families and placement in foster care can affect children (positively and negatively), and what programs are effective at preventing or treating child maltreatment.

Yet we are not much closer than we were decades ago to understanding how legal variations affect what happens in child protection cases. The most widely available data does not include important

Correspondence: jgkagan@law.sc.edu 
legal steps - like what court hearings are held and what decisions courts make-and nearly all studies decline to test the effect of legal variables on case outcomes. These data gaps are especially problematic because they undermine the ability of research to impact policy. If research does not engage with the "real-life social work with children and families" then it will be difficult to translate research to practice. "Real-life" child protection practice involves the law and legal systems and so is an essential topic for study.

Enormous outcome differences exist between jurisdictions at every stage of child protection cases. These differences are so large that varying state laws, administrative agencies, and family courts, rather than demographic or socioeconomic differences, likely explain most of the differences. For instance, Missouri authorities deemed 1.3 out of every 1,000 children to be abuse or neglect victims in 2013; the figure was 7.5 times higher in neighboring Illinois, 12 times higher in neighboring Iowa, and 15 times higher in neighboring Kentucky. ${ }^{2}$ The percent of children labeled victims whose cases were brought to court by state agencies ranged from 2.2 percent in Mississippi to 61.6 percent in New Hampshire. ${ }^{3}$ The percent of children labeled victims who state agencies removed from their families and placed in foster care ranged from 5.5 percent in Illinois to 91.5 percent in Florida. ${ }^{4}$ The median time between a termination of parental rights and adoption finalization ranges from under one month in Rhode Island to 14.1 months in Illinois. ${ }^{5}$ New York's and Florida's child populations are nearly identical, ${ }^{6}$ but there were fifty percent more adoptions from foster care in Florida, ${ }^{7}$ and sixty-eight percent more children listed as "waiting" for an adoption in New York. ${ }^{8}$

This article is a call for empirical research to address these and other differences and evaluate whether and to what extent legal differences between states cause different outcomes - and therefore what legal reform efforts might be expected to have the most significant impact. It is also a call for reform of the existing child protection data reporting rules to include key legal data points - a reform which would facilitate study of the law as an independent variable.

\section{EMPIRICAL STUDIES OF LEGAL VARIABLES WOULD BE VALUABLE AND WORTH THE COST}

The importance of studying the effect of the law and legal systems on what happens to children and families in child protection cases is straightforward: Child protection is a multidisciplinary field, in which the law and legal systems play prominent roles, and in which those roles are presumed to matter significantly. To handle individual cases, we spend billions of dollars operating family court systems, paying lawyers, and documenting decisions. To set policy, we litigate disputed legal issues and advocate to state legislatures, Congress, and multiple agencies for desired legal reforms. Understanding what impact child protection laws have and understanding how different legal reforms could affect what happens to children and families, should be an important goal for everyone involved in the system. Greater empirical knowledge would provide direct benefits to policy makers and advocates regarding which laws are optimal and what policies are worth advocating for. Where there is no consensus as to the optimal result, greater empirical knowledge can still assist by focusing debates on laws that have the greatest impact.

Other areas may also be understudied, but child protection law and legal systems are particularly important to research because courts make the most important decisions - whether a child can be removed, whether s/he will reunify, and, if not, what family s/he will live with and what legal status will define that family. Moreover, our child protection law and legal system are designed to balance the fundamental constitutional rights of parents and children to family integrity with the importance of protecting children from parental abuse and neglect; empirical research should help us understand the balance that different policy choices have struck and thus inform further discussions about whether and how to fine tune, or more dramatically reform, that balance.

Putting this argument into practice would impose some challenges. Data reporting systems are expensive to change and to operate, and new data reporting requirements impose a burden on child 
protection agencies. ${ }^{9}$ This section will outline the argument why studying the law's effect on child protection case outcomes is important enough to warrant those costs.

\section{A. STRONGER DATA CAN INFORM SMARTER POLICY CHOICES}

The first, and most obvious, reason for studying the law's impact on case outcomes is to enable better-informed policy choices. Determining which laws make a difference and how they make a difference provides essential knowledge for more informed policy choices by Congress, state legislatures, state and federal agencies, family and appellate courts, and advocates of all stripes.

Some empirical studies could lead directly to policy reforms and confirm or reject the importance of current practices. Research into the effectiveness of subsidized guardianship, for example, led to its expansion nationwide and the provision of federally-supported guardianship subsidies. ${ }^{10}$ Research into other legal variables could similarly lead to reforms. If, for example, studies of the frequency of review and permanency hearings found that somewhat more frequent hearings - say, every four months - correlated to a statistically significant degree with faster and longer-lasting permanency outcomes (i.e., faster reunifications, adoptions, and guardianships, with fewer foster care reentries) and if even more frequent hearings lacked such a correlation, that would provide strong reason for states to follow such a timeline and for the federal government to provide funding to support it. But, if research showed minimal effects from court timelines, that result should trigger reconsideration of the long-standing push for more frequent hearings.

Empirical studies can also sharpen existing policy debates even when they cannot resolve them. Research into the standard of proof at trial-which is a preponderance of the evidence in most states but clear and convincing evidence in 18 states $^{11}$ - illustrates the point. Recognizing that no legal system will reach perfect decisions, standards of proof serve to skew error-a high standard of proof skews error in favor of family integrity and against coercive state intervention, while a lower standard of proof does the inverse. A value judgment about these particular risks is necessary to determine which standard is best. No empirical study can provide that value judgment. But an empirical study into what effect different standards actually have provides an important baseline for discussing that values question.

\section{B. UNDERSTANDING THE LAW'S ROLE IN A MULTIDISCIPLINARY SYSTEM}

Studying the effect of child protection law and legal systems on outcomes could decode which of several overlapping systems has the most impact on outcomes and thus where to best direct reform efforts. In particular, it could reveal whether child protection agencies or family courts have more impact on what happens to children and families. A judge formally makes the most important decisions in a child protection case - whether a child will remain at home or live in foster care, whether a parent has abused or neglected a child, whether a child will reunify with a parent, or live with a guardian or adoptive parent. Surveys of child protection agency caseworkers conclude that they "perceive juvenile court personnel as having influence on the way that they carry out their practices," $" 12$ suggesting that agencies may decide on positions in cases based on what they expect courts would be willing to support. On the other hand, there is no doubt that agencies have significant power over children and families in child protection cases - in particular, they generally decide when to remove children from their families and when to file abuse or neglect petitions. Once a child is in foster care, foster care agencies "bear far greater responsibility for the day-to-day management of cases than does the court,"13 and the agency's position may carry especially strong weight with the court.

But how much do the law and the court system impact the judge's decision, especially compared with agencies? Consider a permanency hearing in a simplified composite case: 
The child protection agency removed Davon, age 8, from his mother 14 months ago based on evidence of his mother's heroin addiction, and placed him with his maternal grandmother. Davon's mother has completed one stint in inpatient drug treatment, then relapsed, then entered and successfully completed another and has tested clean for six weeks. The agency caseworker believes the likelihood that she will relapse again is unacceptably high, and that she has not fulfilled her case plan because she has not obtained long-term housing, remains unemployed, and only recently began mental health treatment. The case worker believes adoption is in Davon's best interest. Davon's grandmother would be willing to raise Davon permanently but opposes terminating Davon's mother's parental rights.

At the permanency hearing, the judge will decide whether Davon will reunify with his mother and, if not, whether the permanency plan will remain reunification or shift to adoption - initiating termination of parental rights litigation - or guardianship. Nonlegal factors will shape these decisions, especially Davon's age, his mother's poverty, and substance abuse history and treatment. The services that Davon and his mother have received - including any service providers' opinionsmay be presented to the judge. The case worker will present the agency's views, which are likely shaped by the agency's regulations, policies (formal and informal), supervision structure, and culture, in addition to the case worker's own judgment. The legal system will filter all of these facts and perspectives through laws governing the provision of counsel to all parties, setting timelines for court hearings, establishing standards for reunification or judging case plan compliance, and providing permanency options (or not) beyond reunification and adoption. Studying state-by-state legal variations will help untangle what effect the law has, especially in comparison to other factors, in cases like this.

More detailed study of the impact - if any — of legal variables could also lead to a clearer debate of how child protection law ought to balance power between courts and agencies. It is possible that the agency's view on Davon's case is more likely to impact the result, regardless of what state law says. If the law enacted by legislators and adjudicated by judges is of little moment, then that requires policy makers to determine if it is proper to delegate so much power to agencies - and if not, what specific checks and balances would be most appropriate.

\section{UNDERSTANDING AND EVALUATING THE RULE OF LAW IN FAMILY COURT}

Empirical studies can provide important information about the rule of law in child protection cases. This is no small issue, as family courts have long been known for their procedural informality and vague legal standards and thus criticized for not following the rule of law or, as an old case put it, for applying "pure shuttlecock law ... for whimsical application to child custody controversies." 14 More modern critiques have argued that family courts feature an insular group of repeat playersfamily court judges, lawyers, and case workers who practice regularly in family court - who are susceptible to group think ${ }^{15}$ and make decisions based on heuristics (cognitive short cuts) that block evaluation of the most important factors in a case. ${ }^{16}$ As a result, they use coercive authority in a therapeutic guise to pressure professionals and parties to acquiesce to state-created plans to break up families pending parental rehabilitation. ${ }^{17}$

These criticisms suggest a cynicism that the law on the books actually matters to what happens in child protection cases and a belief that this insular group of professionals will do what it wishes regardless of legal variations or changes. (Cynics might further argue that the scarcity of studies of the law's effect reflects an understanding throughout the field that the law does not matter.) Either confirming or disproving that cynicism could provide important knowledge to policy makers and advocates. The field would benefit from more comprehensive studies about whether the law really shapes judicial decisions and the actions that agencies and other parties take before coming to court. If not, it would support critics of family court culture - and perhaps support arguments that family courts must reform so that law matters more. If the law matters greatly, then those critiques would require, at a minimum, some refinement. 


\section{CHILD PROTECTION LAW SHOULD BE RIPE FOR EMPIRICAL STUDY}

Child protection law provides a promising field for empirical study because different state laws create easy comparison groups. All states follow the same legal architecture in child maltreatment cases to comply with Supreme Court decisions and federal child protection funding statutes. But important legal variables exist across the familiar legal architecture of child protection investigations, court petitions, adjudications, dispositions, and permanency hearings. With colleagues, I have studied one of these variables in a recent article - the standard of proof applied to state allegations of abuse and neglect at trial. ${ }^{18}$ Scores more variables exist and those variables should be ripe for study. Scholars would have to control for demographic and other differences from one state to another and study the effect of the legal differences between states. States also change some of their laws, making it possible for scholars to perform before and after studies to determine what impact such changes had, if they can control for other variables within such states.

This section discusses a nonexhaustive set of legal variables that should be ripe for empirical study. All of the examples provided identify legal areas regarding which researchers can catalog state laws and policies, and compare outcomes in states that have made different policy choices.

\section{A. CASE PROCESSING TIMELINES}

Child protection law has long sought to make decisions along a child's sense of time- that is, quickly. States now mandate adjudications within relatively short time periods ${ }^{19}$ and federal funding statutes require agencies to develop case plans within 60 days of removing a child. ${ }^{20}$ When reunification does not occur quickly, federal law requires that state courts hold permanency hearings within twelve months of the child's entry into foster care and at least every twelve months after that. ${ }^{21}$ Federal legislation has shortened these timelines. For instance, the Adoption and Safe Families Act shortened the time for holding permanency hearings from 18 months to 12 months, ${ }^{22}$ because Congress concluded "that 18 months is a very long time in the life of a young child." 23

These federal requirements impose minimum standards for state child protection systems; some states go beyond those minimums and have codified more stringent requirements. Some require agencies to complete case plans within the same sixty-day timeline that federal law requires, ${ }^{24}$ while others impose a variety of shorter timelines. ${ }^{25}$ Some states require permanency hearings after twelve months of foster care and every twelve months thereafter, ${ }^{26}$ while others require review hearings within the first year of foster care and more frequent permanency hearings after that first year. ${ }^{27}$

This legislative landscape raises several questions. Do more frequent hearings help achieve permanency faster? If so, is there an ideal hearing timeline? Is providing more frequent hearings a costeffective use of resources? The existing empirical record suggests that more frequent hearings might help, but the record is far from definitive - in large part because no study has compared states with the federal minimum timelines to states which require more frequent hearings. One study confirms, unsurprisingly, that counties with more judicial personnel per case are able to meet statutory hearing timelines better than less well-resourced counties in the same state. ${ }^{28}$ However, the impact of more frequent hearings on actual outcomes is less clear; the higher resourced counties had shorter timelines to adoptions, but no significant difference in the number of cases with a permanent placement of any kind (including reunification) within 15 months. ${ }^{29}$ It is unclear whether the faster adoptions resulted from more frequent hearings or some other difference between the higher and lower-resourced counties. We do not know if courts would comply with requirements for more frequent hearings and, if they would, if these earlier findings would be replicated across the country or if more frequent hearings could be shown to improve reunification timelines generally or to speed adoption or guardianship only or some more complicated relationship. 


\section{B. PROVISION AND ROLE OF COUNSEL}

Child protection law has seen many developments in the provision and role of counsel for both children and parents. As with any appointed counsel system, jurisdictions vary in the fees, caseloads, and other indicators of quality of appointed counsel for both children and parents. State laws also vary in whether they appoint lawyers to represent children's stated wishes or what attorneys believe to be in children's best interests; Jean Koh Peters placed the 50 states and the District of Columbia into six separate categories based on their different statutes regarding representing children. ${ }^{30}$ Certain states have changed their standards - for instance, New York moved from a best interests to stated interests model in $2007^{31}$ - thus permitting before and after comparisons. A recent review found only a small number of studies on the impact of children's legal representation and concluded that prior studies' designs were "seriously flawed." ${ }^{32}$ This should be no surprise because, as that review pointed out, there is "little or no empirical data on the question of what makes a good lawyer" of any kind. ${ }^{33}$ But unlike other areas of law, the representation of children varies significantly by state depending on the statutorily mandated role of such representatives, thus lending itself to interstate comparisons.

States also vary in their provision of counsel for parents; most provide counsel to parents throughout a case but several make appointment of counsel discretionary or do not provide counsel in all cases - avoiding provision of counsel in between an initial disposition and a permanency trial such as a termination of parental rights. ${ }^{34}$ State court litigation has addressed some of these issues in certain states, addressing for instance, the constitutionality of denying parents counsel for the first year or more of case until the state chooses to seek a termination of parental rights. ${ }^{35}$

Comparing different jurisdictions could test the hypothesis that stronger parent representation and stated interest children's representation would lead to results more consistent with parents' and children's wishes - presumably, ${ }^{36}$ fewer adjudications and faster reunifications. Some intrajurisdictional research has suggested that strong parent representation can also speed all permanency outcomes and shorten stays in foster care. ${ }^{37}$ These studies focus on individual programs located in one jurisdiction. Comparing strong right to counsel states - states with strong statutory or case law right to counsel for parents and children, coupled with strong organizations employing lawyers with reasonable caseloads and good training - with weak ones could yield important results and come closer to satisfying the "serious need for rigorous social science research on representation of children [and] representation of parents." 38

\section{SUBSTANTIVE STANDARDS FOR MALTREATMENT, REUNIFICATION, AND TERMINATION}

States vary in the substantive standards they apply in abuse and neglect cases, as scholars have long noted. ${ }^{39}$ Three standards at various stages of a case illustrate the significant variation between states. First, twenty-nine states and the District of Columbia have, by statute or court decision, defined any prenatal exposure to an illegal drug as per se neglect; the remainder do not. ${ }^{40}$ Second, most states do not specify when parents and children are entitled to reunify, but a few states do. South Carolina has a particularly reunification-friendly statute, placing a burden on the child protection agency to establish "compelling reasons" for selecting any permanency plan other than reunification and requiring courts to order reunification when parents have "remedied the conditions that caused the removal" absent "unreasonable risk[s] of harm." 41 Third, states vary in both the number and type of statutory criteria that can support a termination of parental rights. ${ }^{42}$

These differences raise questions that should be studied empirically: Does a statute declaring prenatal drug exposure to be per se neglect lead agencies to remove more infants or file more cases in such situations, or only change how states petition cases? $?^{43}$ Do different standards regarding reunification affect the frequency of that permanency option, agencies' recommendations to courts about whether or when to change to a plan other than reunification, or the speed with which reunification is reached? Do different termination of parental rights statutes affect whether or when states seek 
terminations, or the frequency with which courts grant them? Existing studies do not address these questions.

\section{PERMANENCY OPTIONS}

When reunification is not an option, states vary in what permanency options are available and what financial subsidies will support them. Thirty-seven states offer subsidized kinship guardianship and some of those also offer subsidized nonkinship guardianship. ${ }^{44}$ States vary in their subsidy policies as well-some offer adoption and guardianship subsidies which extend until age 21, and some do not. ${ }^{45}$ Researchers have also observed significant differences between states when it comes to permanency outcomes and the need for a "[b]etter understanding of the reasons for these differences between jurisdictions." 46

Intrastate research has found that offering subsidized guardianship increases the total number of children who leave foster care to permanent homes and changes the balance between permanency options as some families previously pushed to adoption choose guardianship instead. ${ }^{47}$ However, a 2008 federal law expanding funding for subsidized guardianship has not lead to either result nationally. ${ }^{48}$ Comparisons between states with different sets of permanency options and within states that have changed their permanency policies could provide useful insights and perhaps help explain the failure of the 2008 federal law to catalyze national change. Does the power of agencies - some of which continue to offer guardianship relatively rarely, even in states that have subsidized guardianship statutes or policies ${ }^{49}$ - outweigh legal or policy changes? Or do such changes have some impacts, even in the face of some agency resistance?

\section{E. QUESTIONS ABOUT CHILD PROTECTION AGENCY STRUCTURE AND POWER}

Child protection agencies are crucial actors in any child protection case. But these agencies, and their authorities, are not uniform, and state variations exist both in their structure and in their authority compared with family courts. Some states operate statewide systems while others divide child protection agency authority up among county agencies; in the former group, state agencies appoint and supervise local staff, while in the latter group, local elected officials have that authority. ${ }^{50}$ Funding responsibilities between state and county governments can also vary. ${ }^{51}$ Empirical studies could address whether these structural legal differences affect the most important outcome measures, such as child safety and permanency outcomes. ${ }^{52}$

States also vary in the precise balance of power between child protection agencies and juvenile courts, as commentators have long noted. ${ }^{53}$ For instance, do juvenile courts have the power to modify agencies' case plans, or to order agencies to place children in specific homes or to provide particular services, or are those powers reserved to the child protection agency only? ${ }^{54}$ This legal variable raises questions about institutional competencies of courts, Canada and agencies and United Kingdom value of agency deference. But it also raises empirical questions - does court or agency authority enhance placement stability, or permanency or well-being outcomes? That question requires a complex study of results in different jurisdictions, Canada with different rules.

\section{F. POLICIES FOR PSYCHOTROPIC MEDICATION}

Public concern about the likely overmedication of foster children has increased over the past decade, leading Congress to require states to develop policies for oversight of foster children's mental health care through legislation enacted in 2008 and strengthened in 2011. ${ }^{55}$ Before such legislation, states varied widely in both the frequency of foster children's use of psychotropic medication (ranging from $6.4 \%$ to $72.0 \%$ of foster children) and in the frequency of multiple psychotropic medications (which ranged from $0.5 \%$ to $13.6 \%$ of foster children). ${ }^{56}$ Subsequent research has catalogued the wide variety of state policies which resulted. Some involved preauthorization monitoring while 
others featured "red flag" policies to identify possible overmedication after it has occurred. ${ }^{57}$ Most policies have not involved formal agency rulemaking. ${ }^{58}$

We do not know, however, what impact - if any - these new policies are having. We do not know if pre-2008 policy differences, or post-2008 policy changes correlate with psychotropic medication use rates. In the absence of such data it is not surprising that states develop policies in a vacuum: "[T] to identify which approaches improve well-being for youth in foster care." 59

\section{G. COMBINING MULTIPLE, UNITED KINGDOM MEASURES}

A collection of state laws might add up to more than the sum of their parts. For instance, several of the varying standards discussed here reflect more or less protection for parental rights and family integrity. Legislation that imposes a higher standard of proof, a stronger right to counsel, and fees, and narrower definitions of neglect might reflect a legislative judgment that such family integrity protections are the best policy, and that judgment might have a cumulative effect stronger than any of those individual provisions might predict. Empirical research to identify any such cumulative effects would make important contributions.

\section{CHILD PROTECTION'S BIG DATA AND ITS ABSENCE OF LEGAL VARIABLES}

Child protection is now awash in data. As the recently launched Center for State Child Welfare Data at the University of Chicago's Chapin Hall has put it, “[ $t]$ he days of saying 'we just don't have the data' are over." ${ }^{\prime 60}$ Federal funding statutes require states to report huge amounts of data, and many state laws require similar data reporting. More specialized data sets also exist. One result is that the field now features much empirical work. At the same time, existing data has only limited ability to trace children's and families' interactions with the legal system and what impact the law or legal practices might have on their cases. This section will outline available data and its limits and illustrate the challenges those limits create for the empirical study of the law's impact.

\section{A. A MASS OF DATA—BUT NOT ABOUT LEGAL DETAILS}

A brief summary of two of the leading child welfare data systems illustrates both the promise and shortcomings of existing data. ${ }^{61}$ The federal government collects two sets of data from state child protection agencies - through the AFCARS and the NCANDS. Both have catalyzed the collection of a wide range of immensely valuable data, but no meaningful collection of data connected to legal variables.

AFCARS data systems result from a congressional mandate that states report data to the federal government as a condition of receiving federal funding for foster care systems. Federal regulations list the data that states must track, ${ }^{62}$ requiring, for instance, that for every foster child, states track age, race/ethnicity, disability, date of removal, "conditions associated with child's removal," type of placement and caretaker information, permanency plan, date of, and reason for foster care exit. ${ }^{63}$ The Department of Health and Human Services collects different child welfare data for NCANDS from state agencies, and this data provides the basis for many of the most frequently cited federal child protection publications, such as the annual Child Maltreatment reports. ${ }^{64}$ NCANDS provides a wealth of case-specific detail; the Department of Health and Human Services has a twenty-one-page list of all the data points included in each child file. ${ }^{65}$

It is not difficult to envision the wealth of information one can glean from AFCARS and NCANDS, and much academic work has relied upon these data. Challenges to such research remain - such as the difficulty in tracking children longitudinally ${ }^{66}$ and the challenge of incomplete 
or inaccurate data from states ${ }^{67}$ - but these issues have been sufficiently resolved to permit important research. ${ }^{68}$ Researchers at Chapin Hall have compiled much of this data into a multistate foster care data center, permitting more statistically powerful comparisons between states. ${ }^{69}$

Legal variables, however, are conspicuously lacking from both AFCARS and NCANDS data sets. For instance, there is no reporting of the actual statutory forms of abuse or neglect substantiated by the state during its investigation, alleged by the state in family court, or adjudicated by a court; or when the child's case had a hearing in court, whether the court followed the agency's recommendation, or how much time passed from a permanency hearing to the filing of a permanency action. Federal requirements are striking for omitting any legal variables or court system interactions. AFCARS regulations require no legal variables. NCANDS similarly lacks legal variables. Only two data points on its twenty-one-page list of variables relate to the legal system - whether the state filed a petition in the family court, and, if so, when. ${ }^{70}$ What the petition alleges, what hearings follow, and what happens at those hearings is not reported. These omissions are particularly odd for data systems designed for child protection, foster care, and adoption cases, which all require court action to occur, yet no court data was included. The regulations read as if only the state agency's actions and not the court system mattered.

\section{B. RESEARCH LIMITATIONS FROM EXISTING DATA}

The available data can lead to immensely useful studies. Statistical techniques permit comparisons between similarly situated children, and thus enable researchers to study key variables. ${ }^{71}$ Identifying such data sets regarding matched cases in multiple states would be labor intensive, but possible. But use of federal data remains difficult. This section illustrates the limitations of using existing national data sets which make it difficult to test legal variables. This section also notes many researchers' choice to study state data sets so they can access better information about legal variables, and discusses the limitations of using state data sets.

\section{Federal Data Sets}

The absence of legal variables from these large data sets makes studying them difficult. These difficulties are illustrated by a recent study of the impact of different standards of proof on child welfare case outcomes, of which I am a coauthor. Trial standards of proof vary from state to state; most states have a preponderance of the evidence standard, but eighteen have clear and convincing. ${ }^{72}$ The standard of proof is a straightforward and well-understood legal provision, so we should be able to study its impact (if any) fairly directly. But the available data through AFCARS and NCANDS do not contain enough details to do so-we cannot track the children in each data set from investigation to substantiation to petition filing to adjudication. Those data do not even say whether or not a court adjudicated a parent abusive or neglectful. It is easy to see that there are a large number of children removed by state agencies who reunify with their family in a matter of weeks, ${ }^{73}$ but neither AFCARS nor NCANDS reports if these quick reunifications result from state agencies dropping their petitions, judges dismissing petitions, agencies or judges choosing to reunify children after an adjudication, or some other phenomenon. The absence of such data makes it difficult to identify the standard of proof's impact. The same difficulty exists whenever the specific hearings held and legal actions taken are relevant, because AFCARS and NCANDS do not track that data.

Due to these limitations, we turned to yet another data set- the NSCAW. ${ }^{74}$ NSCAW does not track whether a judge adjudicates a child neglected or dismisses a petition, but does report when court appearances occur. We used the existence of hearings after the adjudication hearing as a proxy for the court ruling for the state at adjudication (otherwise it would lack jurisdiction to hold further hearings) ${ }^{75}$ But the NSCAW data set only provides statewide data in eight states, significantly limiting the sample size. ${ }^{76}$ 
As a result of these data limitations, we were only able to reach some tentative conclusions, and with less statistical significance than we had hoped. If federal data enabled us to use a larger sample from more states, we would have likely been able to obtain more robust results. This same challenge would affect the study of some of the variables discussed in Part II. For instance, studying the effect of different case processing timelines from one state to another or the impact of specific neglect definitions would be difficult without having data on what hearings were held when or what specific forms of neglect are alleged in petitions and adjudicated by courts.

\section{State Data Sets}

Other scholars have used data from state agencies and courts to analyze child welfare case outcomes. ${ }^{77}$ These studies review key details reported in state but not national databases. Such studies have been valuable and they suggest that the legal system impacts case outcomes - and thus support further study of legal differences. But these studies have important limitations - they cannot test the effect of legal differences between states. For instance, one study sought to determine the effect of judicial case processing timelines on case outcomes, but did so within only one state. ${ }^{78}$ The result of the study is important-faster hearings correlate with faster case closure. ${ }^{79}$ But the timeline variations resulted from court practices and individual judges' scheduling, not legal differences. Further, by focusing on only one state, the study could not explore whether changing statutory or rule-based timelines would have a similar effect, or which timelines are most important. Another study comparing regional differences within a state concludes that juvenile courts impact which cases get filed and their permanency outcomes. This suggests that the perceived attitudes of judges to particular fact patterns and the timing of court involvement shapes outcomes. ${ }^{80}$ The study leaves unanswered what impact, if any, the law had. A third study examined the effect of model parent representation programs by comparing the case outcomes for such programs with similar cases within the same jurisdiction. ${ }^{81}$ That study found significant benefits to model parent representation, but could not examine whether interstate right to counsel variations had any impact.

\section{MANY EMPIRICAL STUDIES, BUT A DEARTH OF EFFORTS TO STUDY THE DIFFERENCE THAT THE LAW MAKES}

The child protection field has a wealth of empirical studies into a wide range of topics. It also has easily-identifiable legal variables ${ }^{82}$ and a wide and growing set of case-specific data. ${ }^{83}$ Yet the field lacks significant numbers of studies which focus on legal variables and what impact, if any, they have on outcomes. The proliferation of data has led to immensely valuable studies. But, most studies do not look at the law as a variable which could impact outcomes.

A recent meta-review of empirical studies of factors correlated with removing children from their homes and placing them in foster care illustrates the dearth of studies examining the law. The metareview examined studies of 75 data sets. The strong majority of these studies reviewed only one city, county, or state, precluding comparison of jurisdictions with different legal standards defining maltreatment or for substantiating maltreatment or removing children. ${ }^{84}$ The other studies did not focus on the law as a possible explanation for removals. ${ }^{85}$ Studies which do use data sets involving children subject to different laws typically study variables other than those laws. ${ }^{86}$

The dearth of studies is evident in the leading journals focusing on the children protection system, such as this journal, Children and Youth Services Review, Child Maltreatment, Child Welfare, or the Journal of Public Child Welfare. Any issue of those journals will likely include high-quality and important empirical studies. But these studies generally do not use the law as an independent variable to study legal differences between states or the impact of a new law within one state. Some studies note legal variations between states and use multistate data sets but do not explore whether those legal variations explain different practices or outcomes. ${ }^{87} \mathrm{~A}$ review of all titles published in the past 
five years of those five journals found only four articles ${ }^{88}$ treating the law as an independent variable. ${ }^{89}$ Searches for the term "law" and "legal" on Chapin Hall's Center for State Child Welfare Data website revealed only one study, which did not address legal variations between states. ${ }^{90}$

Several studies illustrate the possibility of studying the effect of interstate legal differences and how scholars have not yet chosen to study those. For instance, one study surveyed more than 15,000 older foster youth from every state who are tracked by states in the National Youth in Transition Database and sought to identify variables that predict whether the youth become teen parents. ${ }^{91}$ The study did not ask if they lived in a state which extended foster care to age twenty-one or had any other legal variable that might affect that outcome. ${ }^{92}$ Another study identified some variables correlated with the size of racial disparities in the families subject to child protection investigations. The study tested whether poverty rates, state diversity, and other nonlegal factors affected the resultsnot whether different standards of proof, neglect definitions, or other laws might shape the racial makeup of investigated families. ${ }^{93}$ These studies would be even more valuable if they, or subsequent studies, addressed relevant legal variables.

Legal journals focused on children's issues tend to have few empirical pieces at all, but their legal focus could possibly lead them to publish more pieces studying the impact of legal variations. But they do not do so. A review of the past five years of the U.C. Davis Journal of Juvenile Law \& Policy, Family Law Quarterly, the Whittier Journal of Child and Family Advocacy, and the Children's Legal Rights Journal found no empirical studies of the effect of the law. The same is true of several important compilations of child protection research published in the years following the emergence of the data sets discussed in Part II. These works rightly extolled the virtue of the empirical studies that could be done with the new and improved data sets and predicted that the studies that would emerge would prove essential to policy reform efforts. ${ }^{94}$ Yet none of these works included any studies of the effect of legal variations across the nation.

There are a few studies that focus on legal variables illustrating how valuable such research can be. For instance, in the mid-1990s, Martin Guggenheim studied the changes which occurred in states that experimented with expedited termination of parental rights, in a study that has been frequently cited and coined the term "legal orphan," which continues to impact child protection law and policy discourse. ${ }^{95}$ Susan Mangold and others have studied the impact of different funding regimes on permanency outcomes. ${ }^{96}$ Mary Eschelbach Hansen and I have studied the correlation of adoption subsidies offered past age eighteen to overall adoption rates. ${ }^{97}$

\section{CONCLUSION: STUDY THE LAW AS AN INDEPENDENT VARIABLE AND REFORM DATA SETS TO FACILITATE SUCH STUDY}

The child welfare field includes thousands of lawyers, judges, and professionals and advocates of varying stripes who believe that the child welfare law matters to child welfare outcomes. It is believed that whether permanency hearings are held within twelve or eighteen months, when counsel is appointed for parties, what a state legislature defines as neglect, and a host of other legal variables matters. Empirical evidence is, for good reason, increasingly used to shape child welfare practice and it should be used to help evaluate legal differences among states. But it is not yet used that way because the field simply has not developed the empirical tool kit to study them. This Article is a call for that to change.

Studying the effect of the law would be easier if the major child welfare databases tracked key legal variables. A comprehensive review of child welfare cases and outcomes cannot ignore the role of the law and the legal system, yet current data tracking fails to measure essential details. The federal government should review and revise its regulations and policy guidance to facilitate greater study of legal variables. To begin, NCANDS data should include a state specific reference to the type of abuse or neglect alleged in a petition, what adjudication occurred, when hearings were held, and what type they were. The federal government should provide financial assistance to state child 
protection agencies to help them develop the requisite databases and accurate data-tracking mechanisms.

But scholars should not wait for such reforms to focus on the study of the law's impact; the value of such study is so great that it should expand now. Innovative studies can develop data sets which can be shared and which can provide important insights to current questions in child welfare law. And some issues do not need reforms to data sets. The key legal variables can be found in comparing state statutes and regulations, and valuable work can begin immediately.

\section{NOTES}

* I thank Mary Eschelbach Hansen and Avni Gupta-Kagan for reviewing early drafts and Matt Hodge for research assistance.

1. Mark F. Testa et al., Bridging the Gap Between Research and Practice: The Work of the Steering Team for the Child Welfare Research and Evaluation Translational Framework Workgroup, 8 J. PuB. Child Welfare 333, 334 (2014).

2. U.S. Dep't of Health \& Hum. Serv., Administration for Children and Families, Administration on Children, Youth and Families, Children's Bureau, Child Maltreatment 2013, 33 (2014), http://www.acf.hhs.gov/sites/default/files/cb/cm2013.pdf.

3. Id. at 89 .

4. Id. at 87 .

5. U.S. Dep't of Health \& Human Serv., Administration for Children and Families, Administration on Children, Youth and Families, Children's Bureau, Time between Termination of Parental Rights (TPR) and Adoption Finalization: October 1, 2012 to September 30, 2013 (FY 2013) (2014), http://www.acf.hhs.gov/sites/default/files/cb/tpr2013.pdf.

6. The Annie E. Casey Foundation Kids Count Data Center reports that Florida had 4,031,576 children and New York 4,250,790 in 2013. Data are available by following state links at http://datacenter.kidscount.org/.

7. In FY 2013, there were 3,417 adoptions from foster care in Florida and 2,184 in New York. U.S. Dep't of Health \& Human Serv., Administration for Children and Families, Administration on Children, Youth and Families, Children's Bureau, Adoptions of Children with Public Child Welfare Agency Involvement by State FY 2004-FY 2014 (2015), http://www.acf.hhs. gov/sites/default/files/cb/children_adopted2014.pdf.

8. There were 5,843 waiting children in New York and 3,458 in Florida. U.S. Dep't of Health \& Human Serv., Administration for Children and Families, Administration on Children, Youth and Families, Children's Bureau, Children in Public Foster Care on September 30th of Each Year Who Are Waiting to be Adopted (2014), http://www.acf.hhs.gov/sites/default/files/cb/ children_waiting2012.pdf.

9. Desired changes to federally required data reporting are discussed in Part IV, infra.

10. Mark F. Testa \& John Poertner, Evaluation of Child Welfare Interventions, in Fostering AccountaBiLITY: Using Evidence to Guide and Improve Child Welfare Policy 195, 196-200 (Mark F. Testa \& John Poertner eds., 2010) [hereinafter Fostering AcCountability].

11. Ashley J. Provencher et al., The Standard of Proof at Adjudication of Abuse or Neglect: Its Influence on Case Outcomes at Key Junctures, 17 Soc. Work \& Soc. ScI. Rev. 22, 27 (2014).

12. Raquel T. Ellis, Child Welfare Workers'Perceptions of Juvenile Court Influence on Child Welfare Practices, 4 J. PuB. Child Welfare 158, 168 (2010). Notably, this study surveyed child protection workers in one county in one state, and thus did not test whether state legal differences or practice differences between court systems could affect the results. Id. at 161 .

13. Sarah J. Beal et al., Judicial Case Management in Predicting the Length of Stay in Foster Care, 44 CHILD. \& YoutH SERV. Rev. 16, 16 (2014). Beal et al. concluded that, despite agencies' significant role, courts can make a difference in case outcomes. Id. at 19 .

14. Ernst v. Flynn, 129 N.W.2d 430, 439 (Mich. 1964).

15. Melissa L. Breger, Making Waves or Keeping the Calm?: Analyzing the Institutional Culture of Family Courts Through the Lens of Social Psychology Groupthink Theory, 34 Law \& Psychol. Rev. 55, 61-62 (2010).

16. Matthew I. Fraidin, Decision-Making in Dependency Court: Heuristics, Cognitive Biases, and Accountability, 60 Clev. St. L. Rev. 913, 938-39 (2013).

17. Amy Sinden, "Why Won't Mom Cooperate?": A Critique of Informality in Child Welfare Proceedings, 11 YALE J.L. \& Feminism 339, 343-44 (1999).

18. Infra Part IV.B.1.

19. E.g., D.C. Code $\S 16-2316.01(b)(1)(2000)$.

20. 45 C.F.R. $\S 1356.21(\mathrm{~g})(2)(2012)$.

21. 42 U.S.C. $\S 675(5)(C)(2015)$.

22. Adoption and Safe Families Act of 1997, Pub. L. No. 105-89, 111 Stat. 2115, § 302.

23. H.R. REP. No. 105-77, pt. 2, at 13 (1997), as reprinted in 1997 U.S.C.C.A.N. 2739, 2745-46.

24. E.g., 55 Pa. Code $\S 3130.61$ (West 2015).

25. 705 Ill. Comp. Stat. 405/2-10.1 (2016) (forty-five days); Ark. Code Ann. § 9-27-402 (1987) (thirty days); S.C. CodE ANN. 63-7-1680 (1976) (ten days of removal hearing). 
26. E.g., S.C. CodE ANN. § 63-7-1700(A), (I)(3), (I)(5) (1976) (requiring a permanency hearing within twelve months and subsequent permanency hearings annually).

27. Missouri, for instance, requires juvenile courts to hold dispositional review hearings every 90 to 120 days during the first twelve months of a case and to hold permanency or permanency review hearings every six months thereafter. Mo. SuP. CT. R. 124.01(b) https://www.courts.mo.gov/page.jsp?id=1411 (last visited May 11, 2016).

28. Steve M. Wood et al., The Effects of Judicial Personnel on Hearing and Outcome Timeliness in Juvenile Dependency Cases, 52 Fам. Ст. Rev. 90, 95-96 (2014).

29. Id.

30. Representing Children Worldwide: Research Summary, www.law.yale.edu/rcw/rcw/us_summary_chart.ppt (last visited Mar. 9, 2016).

31. Administrative Order of the Chief Judge of the State of New York, 17 Oct. 2007, http://www.courts.state.ny.us/rules/ chiefjudge/section7.2_amend.pdf, codified at Rules of the Chief Judge § 7.2, Function of the attorney for the child.

32. Donald N. Duquette \& Julian Darwall, Child Representation in America: Progress Report from the National Quality Improvement Center, 46 FAM. L.Q. 87, 119 (2012).

33. Id. at 120 .

34. Vivek Sankaran, A National Survey On A Parent's Right to Counsel in Termination of Parental Rights and Dependency Cases, http://youthrightsjustice.org/Documents/SurveyParentRighttoCounsel.pdf (last visited May 11, 2016).

35. In re T.M., 319 P.3d 338 (Haw. 2014).

36. Stating what children's wishes are in the aggregate is a difficult proposition, as some will want to live with a parent and others not; the statement in the text presumes that most children would desire to remain with their parent or caregiver.

37. Elizabeth Thornton \& Betsy Gwin, High-Quality Legal Representation for Parents in Child Welfare Cases Results in Improved Outcomes for Families and Potential Cost Savings, 46 FAM. L.Q. 139 (2012).

38. Duquette \& Darwall, supra note 32, at 119.

39. E.g., Nico Trocme, Epidemiology of Child Maltreatment, in Child Welfare Research: Advances for Practice And Policy 15-16 (Duncan Lindsey \& Aron Shlonsky eds., 2008) (describing lack of "consensus on a specific set of common diagnostic categories" for child abuse or neglect as a result, at least in part, of varying state definitions).

40. Transcript of ABA Section of Litigation Children's Rights Litigation Committee and Center for Professional Development, Pot, Parenting and Government Intervention, May 18, 2015.

41. S.C. Code AnN. § 63-7-1700(C)-(D) (1976).

42. William Vesneski, State Law and the Termination of Parental Rights, 49 FAм. Cт. Rev. 364 (2011).

43. One 2001 study found significant variation in different agencies' responses to drug-exposed infants, but did not explore whether variations correlated with different state statutes. Steven J. Ondersma et al., Child Protective Services' Response to Prenatal Drug Exposure: Results from a Nationwide Survey, 25 ChILd ABuse \& NeGLect 657 (2001).

44. Josh Gupta-Kagan, The New Permanency, 19 U.C. Davis J. Juv. L. \& PoL’y 1, 14, 20-21 (2015).

45. Mary Eschelbach Hansen \& Josh Gupta-Kagan, Raising the Cut-Off: The Empirical Case or Extending Adoption and Guardianship Subsidies from Age 18 to 21, 13 U.C. Davis J. Juv. L \& PoL’y 1, 13-14 (2009).

46. Mark E. Courtney \& Jennifer L. Hook, Timing of Exits to Legal Permanency from Out-of-Home Care: The Importance of Systems and Implications for Assessing Institutional Accountability, 34 CHILD. \& Youth SeRv. Rev. 2263, 2263 (2012).

47. Gupta-Kagan, supra note 44, at 13-17.

48. Id. at 30 .

49. Id. at $32-34$

50. Compare, e.g., S.C. CoDE $§ 43-3-40$ (1976) (granting the state Department of Social Services Director authority to hire and fire county directors) and OHIO Rev. CoDE ANN $§ 5153.02$ \& 5153.16 (West 2015) (requiring counties to have child protection agencies and granting those county agencies authority over child protection investigations and responsibility for foster children).

51. Kerry DeVooght et al., Federal, State, and Local Spending to Address Child Abuse and Neglect in SFY 2012, 13, http://www.childtrends.org/wp-content/uploads/2014/09/2014-47ChildWelfareSpending2012.pdf (last visited Aug. 7, 2015) (noting that California "shifted responsibility for child welfare funding to localities" in 2011).

52. One study correlated funding differences with permanency outcome differences. Susan Vivian Mangold et al., Using Community Based Participatory Research to Study the Relationship between Sources and Types of Funding and Mental Health Outcomes for Children Served by the Child Welfare System in Ohio, 21 J.L. \& PoL'y 113 (2012).

53. E.g., Bruce A. Boyer, Jurisdictional Conflicts Between Juvenile Courts and Child Welfare Agencies: The Uneasy Relationship Between Institutional Co-Parents, 54 MD. L. REv. 377 (1995).

54. Compare, e.g., In re B.L.J., 717 P.2d 376 (Alaska 1986) (limiting family court's authority over foster child's specific placement) with In re Robert A., 4 Cal. App. 4th 174 (Calif. Ct. App. 1992) (holding that family court make direct a specific placement).

55. Kathleen Noonan \& Dorothy Miller, Fostering Transparency: A Preliminary Review of "Policy" Governing Psychotropic Medications in Foster Care, 65 Hastings L.J. 1515, 1517 (2014).

56. David Rubin et al., Interstate Variation in Trends of Psychotropic Medication Use Among Medicaid-Enrolled Children in Foster Care, 34 Child. \& Youth Serv. Rev. 1492, 1495-96 (2012).

57. Id. at 1519. See also Thomas I. Mackie et al., Psychotropic Medication Oversight for Youth in Foster Care: A National Perspective on State Child Welfare Policy and Practice Guidelines, 33 Child. \& Youth Serv. Rev. 2213 (2011) (categorizing states' various policies). 
58. Noonan \& Miller, supra note 55, at 1519.

59. Mackie et al., supra note 57, at 2218.

60. The Center for State Child Welfare Data, About Us, https://fcda.chapinhall.org/about-us/(last visited May 11, 2016).

61. A full exploration of the alphabet soup of child welfare data sets and reports is beyond the scope of this article. Those data sets and reports include AFCARS (Adoption and Foster Care Analysis and reporting System), SACWIS (Statewide Automated Child Welfare Information System), NCANDS (National Child Abuse and Neglect Data System), NSCAW (National Survey of Child and Adolescent Well-being), and the National Youth in Transition Database.

62. 45 C.F.R. $\S \S 1355.40$, App. A \& App. B (2015).

63. Id. at App. A.

64. ChildREN's BurEAu, NCANDS, (June 18, 2015), http://www.acf.hhs.gov/programs/cb/resource/about-ncands.

65. Children's Bureau, NCANDS Child File Codebook (Sept. 2015), available at http://www.acf.hhs.gov/programs/cb/ resource/ncands-child-file.

66. Richard Barth et al., for instance, criticize AFCARS data for failing to provide any cohort analysis of foster children, making it difficult to track how cases proceed through the legal system. Richard P. Barth et al., From Anticipation to Evidence: Research on the Adoption and Safe Families Act, 12 VA. J. Soc. PoL'y \& L. 371, 379 (2004).

67. See, e.g., U.S. Dep't of Health \& Hum. Serv., Final Report: South Carolina Child and Family Services Review, 4 (2010) (criticizing poor "[p]olicy and practice standards" regarding data tracking "which results in inaccurate data").

68. Researchers have "successfully constructed the necessary longitudinal data bases" from these data files and can now work with state data systems to study individual cases over time. Tom McDonald \& Mark F. Testa, Outcomes Monitoring in Child Welfare, in Fostering Accountability, supra note 10, 101, 126; Mark Testa et al., Can AFCARS Be Rescued? Fixing the Statistical Yardstick that Measures State Child Welfare Performance (2008), available at http://cfrc.illinois.edu/pubs/rp_ 20080301_CanAFCARSBeRescuedFixingTheStatisticalYardstickThatMeasuresStateChildWelfarePerformance.pdf.

69. See The Center for State Child Welfare Data, https://fcda.chapinhall.org/(last visited May 11, 2016).

70. Id. at 11 .

71. The various statistical techniques are explained in multiple publications and need no repetition here. E.g., Mark F. Testa, Evaluation of Child Welfare Interventions, in Fostering ACCOUNTABILITY, supra note 10, 199, 206.

72. The results of our study can be found in Provencher et al., supra note 11.

73. In the most recent fiscal year for which AFCARS reports data, 26,263 children left foster care within one month of entering, and 35,963 left between one and five months after entering. U.S. Dep't of Health \& Hum. Serv., The AFCARS Report: Preliminary FY 2013 Estimates as of July 20143 (2014).

74. Researchers have recognized NSCAW as a valuable data set which enables study of a cohort of children over multiple years. Ron Haskins et al., Using High-Quality Research to Improve Child Protection Practice: An Overview, in Ron HaSkINs et al., Child Protection: Using Research to Improve Policy and Practice 3 (2007). It also can gather data that can fill in the gaps from NCANDS. Cecilia Casanueva et al., Examining Predictors of Re-Reports and Recurrence of Child Maltreatment Using Two National Data Sources, 48 Child. \& Youth Serv. Rev. 1, 2 (2015).

75. Provencher et al., supra note 11, at 32.

76. Id. at 49. NSCAW also only includes cases that began at a particular period of time, so we could not control for any time-specific variables that could have shaped adjudication rates.

77. E.g., Andrew Zinn \& Gretchen Cusick, Juvenile Court Pathways to Legal Permanence for Children in Substitute Care, 36 Child. \& Youth Serv. Rev. 90 (2014) (studying cases in Cook County, Illinois); Trudy Festinger, The Influence of an Adoption Experiment on Social Policy, in Child Welfare Research: Advances for Practice and Policy 99 (Duncan, Lindsey \& Aron Shlonsky eds., 2008) (studying a New York State court processing change); Mark F. Courtney \& Joan Blakey, Examination of the Impact of Increased Court Review on Permanency Outcomes for Abused and Neglected Children, 41 FAM. Cт. Rev. 471 (2003) (studying the Dane County, Wisconsin Court Improvement Project); Clark M. Peters, Examining Regional Variation in Extending Foster Care Beyond 18: Evidence from Illinois, 34 Child. \& Youth Serv. Rev. 1709 (2012) (studying variations within Illinois).

78. Beal et al., supra note 13 , at 17.

79. Id. at 18 .

80. Courtney \& Hook, supra note 46.

81. Mark E. Courtney \& Jennifer L. Hook, Evaluation of the Impact of Enhanced Parental Legal Representation on the Timing of Permanency Outcomes for Children in Foster Care, 34 ChiLd. \& Youth Serv. Rev. 1337 (2012).

82. Supra Part III.

83. Supra Part IV.

84. Kish Bhatti-Sinclair \& Charles Sutcliffe, Challenges in Identifying Factors Which Determine the Placement of Children in Care? An International Review, 30 Child \& Adolescent Soc. Work J. 345, 348-52 (2013).

85. See id. at 354-55 (listing variables that appear to impact placement decisions and not discussing any legal variables).

86. E.g., Andrea S. Meyer et al., Substance Using Parents, Foster Care, and termination of Parental Rights: The Importance of Risk Factors for Legal Outcomes, 32 ChILD. \& Youth SERv. Rev. 639 (2010) (studying nonlegal factors for the their impact on legal outcomes, but not legal factors).

87. For example, consider an otherwise excellent study on the frequency of police investigation of child maltreatment allegations. Theodore P. Cross et al., Criminal Investigations in Child Protective Services Cases: An Empirical Analysis, 20 CHILD Maltreatment 104 (2015). The authors explain many of the legal variations among state statutes regarding when law 
enforcement should be involved in a child maltreatment investigation. $I d$. at 105,110 . And the authors study whether local cooperation - in the form of child protection agency and policy memoranda of understanding, joint training, colocation, or child advocacy center availability — affects the frequency of police involvement. Id. at 109-12. But the study does not explore if statutory differences affects that outcome.

88. I exclude from this count articles which study a topic related to a legal variable but not the legal variable itself. For instance, one article studied the effectiveness of a law school's parent representation clinic as compared with that jurisdiction's normal method of representing similarly situated parents. Wendy Haight et al., The Child Protection Clinic: A Mixed Method Evaluation of Parent Legal Representation, 56 Child. \& Youth Serv. Rev. 7 (2015). The variable here was the method of legal services delivery_law school clinic or regular attorney — not law governing the provision of counsel for parents.

89. One compared the frequency with which young adults who emancipated from foster care had criminal justice system involvement, comparing results in two states that end foster care at age eighteen and one state that continues it until twentyone- thus testing whether providing foster care from eighteen to twenty-one affects later criminal justice system contact. Joann S. Lee et al., Formal Bonds During the Transition to Adulthood: Extended Foster Care Support and Criminal/Legal Involvement, 6 J. Pub. Child Welfare 255 (2012). That study found "limited evidence" that foster care until twenty-one reduces women's chances of criminal justice system involvement, but no evidence of such an effect for men. Id. at 273. Another compared state child welfare expenditures with foster care outcomes and found some significant correlations, concluding "that between at least a tenth and up to more than a quarter of the variability among states in these foster care outcomes can be explained by differences in expenditures." Jesse Russell, Child Welfare Finance and Foster care Outcomes, 9 J. Pub. Child Welfare 134, 148 (2015). (This study addressed spending, not legal differences per se, but I include it to err on the side of a larger count.)

Two articles addressed a topic that had garnered significant public attention- the scope of mandatory reporting laws in the aftermath of the Penn State sex abuse scandal — and asked whether variations in state laws affected reporting rates or report disposition outcomes. Intriguingly, the studies used different data sets and reached different conclusions-suggesting the need for more research on this topic. Kathryn S. Krase \& Tobi A. DeLong-Hamilton, Comparing Reports of Suspected Child Maltreatment in States With and Without Universal Mandated Reporting, 50 Child. \& Youth Serv. Rev. 96 (2015) (finding "no differences in the rate of report or report disposition"); Vincent J. Palusci \& Frank E. Vandervort, Universal Reporting Laws and Child Maltreatment Report Rates in Large U.S. Counties, 38 Child. \& Youth Serv. Rev. 20 (2014) (finding universal reporting states "have significantly higher rates of total and confirmed reports").

90. Search performed on https://fcda.chapinhall.org/on Aug. 19, 2015. The search yielded one study, which was written in 2005 and examined the impact of a federal law on national adoption rates, with no comparisons between states. Fred Wulczyn et al., Adoption Dynamics: An Update on the Impact of the Adoption and Safe Families Act, Chapin Hall (2005), https://fcda. chapinhall.org/wp-content/uploads/2012/10/2005_adoption-dynamics.pdf.

91. Svetlana Shpiegel, Adolescent Parents in the First Wave the National Youth in Transition Database, 9 J. PuB. CHILD WELFARE 277, 283 (2015).

92. Id.

93. Kerrie Ocasio et al., An Exploration of Child Welfare Investigation Disparity Differences Between States, 7 J. PuB. Child Welfare 79, 83 (2013).

94. Fostering Accountability, supra note 10; Child Welfare Research: Advances for Practice and Policy (Duncan Lindsey \& Aron Shlonsky eds., 2008); Child Welfare for the 21st Century: A Handbook of Practices, Policies, and Programs (Gerald P. Mallon \& Peg McCartt Hess eds., 2005).

95. Martin Guggenheim, The Effects of Recent Trends to Accelerate the Termination of Parental Rights of Children in Foster Care-An Empirical Analysis in Two States, 29 FAM. L.Q. 121, 122 (1995).

96. Susan Vivian Mangold et al., Using Community Based Participatory Research to Study the Relationship between Sources and Types of Funding and Mental Health Outcomes for Children Served by the Child Welfare System in Ohio, 21 J.L. \& POL'y 113 (2012).

97. Eschelbach Hansen \& Gupta-Kagan, supra note 45.

Josh Gupta-Kagan is an assistant professor at the University of South Carolina School of Law and is affiliated with the law school's children's law Concentration. His research focuses on child protection and juvenile justice law and has included collaborations with economists regarding the impact of extending adoption subsidies for foster children to age twenty-one and the effect of states' varying standards of proof on child protection cases. He has taught juvenile justice and child protection law school clinics and practiced at the Children's Law Center of Washington, DC, for six years. 